\title{
Erasmus syndrome presented as CREST syndrome with Scl-70 positivity: a case report
}

\author{
Felipe de Lacerda Pereira 1, João Vitor Miranda Portilho 2, João Paulo Viana de Rezende Meira 2, \\ Carmen Dea Ribeiro de Paula 1
}

\author{
${ }^{1}$ Medical School, University Center of Brasília, Federal District, DF, Brazil. \\ ${ }^{2}$ Medical School, Federal University of Goiás, Goiás, GO, Brazil. \\ * Corresponding author: Felipe de Lacerda Pereira. Octogonal 4, Bl F, 116. Zip Code: 70660-046 Federal District, \\ DF, Brazil. Phone: +55 (61) 9 9947-7400. E-mail: felipelacerdape@gmail.com.
}

Research Ethics Committee Approval (if necessary): We declare that the patient approved the study by signing an informed consent form and the study followed the ethical guidelines established by the Declaration of Helsinki.

Received on: Jul 23, 2021. Accepted on: Aug 05, 2021. Available online: Aug 6, 2021.

Abstract
Erasmus syndrome is a rare pathology defined as a systemic sclerosis secondary to
contact with silica, associated or not with silicosis. More recent studies have related
silica as an environmental factor stimulating different immune responses of the body.
This report was made with the objective of presenting a rare case of systemic
sclerosis, in a localized cutaneous form, also called CREST syndrome. A patient with
a 20-year history of mining developed silicosis, cutaneous calcinosis, Raynauld's
phenomenon, esophagopathy, sclerodactyly, telangiectasias and high positivity for
the antitopoisomerase I antibody, the most common antibody in the systemic form.
Keywords: Erasmus Syndrome; CREST; Systemic Sclerosis; Silica; Scl-70.

\section{Introduction}

Erasmus syndrome is defined by the development of systemic sclerosis (SSc) secondary to silica, with or without the presence of silicosis [1]. SSc is conceptualized as a pathology of connective tissues, evidenced by cutaneous and visceral fibrosis of different systems, including vascular [2].

The development of SSc was first evidenced by contact with silica by Bramwell in 1914 [3], but it was officially reported only in 1957 by Erasmus. There are different factors associated with the development of the etiopathogenesis of SSc. Environmental factors, for decades, have been considered as potential influencers in their development [1]. Silica and organic solvents are most often linked to this process. The estimated combined 
relative risk (ERRC) in relation to silica was 3.20 (95\% CI 1.89 - 5.43) for men undergoing meta-analysis [4].

Genetic susceptibility has been presented as the most relevant factor in the manifestation of this disease, most often histocompatibility complex polymorphisms, mostly linked to HLA antigens, class 2. Endocrinological factors such as hormonal interactions have been studied as they are more frequent in women, however, there are still no conclusions [5].

Inhalation of silica particles is related to the development of different pathologies such as silicosis, chronic renal failure, chronic lung disease and simultaneously increased risk of development of pulmonary tuberculosis and also autoimmune diseases, such as rheumatoid arthritis, systemic lupus erythematosus and, as evidenced in this case, systemic sclerosis [6]. Thus, it is believed that, although Erasmus syndrome is not fully understood, the constant pulmonary inflammatory state due to contact with silica may be responsible for generating the immune response of affected patients.

SSc is considered rare, with records of 19 cases per million [7]. Erasmus syndrome, in this way, becomes even less frequent, as was evidenced in a cohort of 947 patients with SSc, nine had Erasmus syndrome, with clinical manifestations of Raynaud's phenomenon, interstitial lung disease and esophageal dysmotility
[8]. The patient reported in the case has similar symptoms, corroborating the manifestations and evolution with the disease's etiopathogenesis.

\section{Case report}

Male, 55 years old, retired, previous occupation in emerald mining for 20 years, with important contact with explosive smoke. Previously he was diagnosed with silicosis due to manifestations such as dyspnea on minimal exertion, paroxysmal nocturnal dyspnea, coughing with wheezing, ventilatory-dependent chest pain in both hemithorax and asthenia. With similar complaints of dyspnea on exertion, associated with cough and fever, he was admitted for investigation. He also reported dysphagia for solids for 2 months, loss of $6 \mathrm{~kg}$ in one year and itchy eyes.

On examination, xerophthalmia, thrush, thickening and skin dryness (absent fold sign), trunk telangiectasias, sclerodactyly, second left finger ulcer and Raynaud's phenomenon were observed (Figures 1 and 2). Total Skin Score (Modified Rodnan score) scored 31. In family history, mother with rheumatism (sic) and thyroid disease, hypertensive and diabetic sister, hypertensive father and deceased due to acute myocardial infarction.

Tests carried out showed Anti-Ro + (407), Anti-La + (357), reagent VDRL $1 / 2$, anti-Scl $70+(201)$ and dotted nuclear FAN pattern. Spirometry showed a 
marked decrease in Forced Vital Capacity and negative bronchodilator test, compatible with restrictive ventilatory disorder. Upper digestive

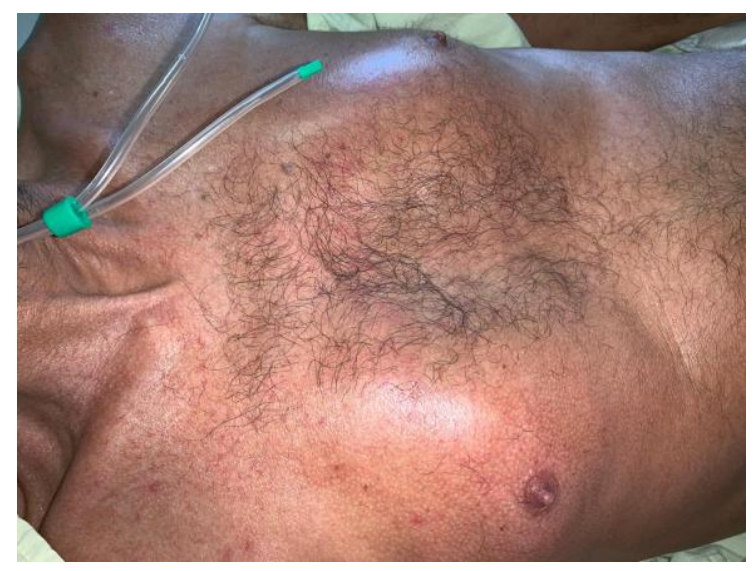

Figure 1: Trunk telangiectasias.

Tests carried out showed Anti-Ro + (407), Anti-La + (357), reagent VDRL $1 / 2$, anti-Scl $70+(201)$ and dotted nuclear FAN pattern. Spirometry showed a marked decrease in Forced Vital Capacity and negative bronchodilator test, compatible with restrictive ventilatory disorder. Upper digestive endoscopy revealed Los Angeles grade A erosive esophagitis and moderate enanthematous pangastritis.

Chest CT compatible with complicated silicosis, associated with an inflammatory process with tomographic criteria for active disease. Radiography of the stomach, esophagus and duodenum showed Rezende group 3 megaesophagus. Skin biopsy (dorsum of the hand) showed chronic dermatitis with superficial and deep lymphplasmocytic inflammatory endoscopy revealed Los Angeles grade A erosive esophagitis and moderate enanthematous pangastritis.

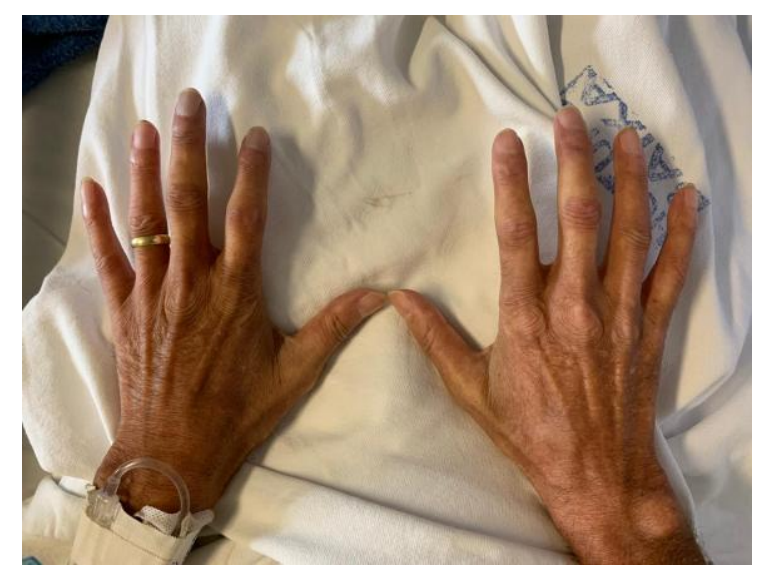

Figure 2: Sclerodactyly.

infiltrate associated with hyalinization of dermal collagen.

\section{Discussion and Conclusion}

Systemic sclerosis can be presented with skin involvement characterized by CREST syndrome, whose initials represent Cutaneous Calcinosis, Raynauld's phenomenon, Esophagopathy, Sclerodactyly (sclerodactyly) and Telangiectasias [8-9]. Any of these manifestations can be the initial one. Usually, the first manifestations are Raynauld's phenomenon and sclerodactyly. This form is considered the benign form of systemic scleroderma. Forms with greater cutaneous involvement lead to symmetrical lesions, diffuse trunk involvement, decreased oral cleft, as 
well as sclerodactyly, Raynauld's phenomenon and telangiectasias [9].

IDespite the diagnosis, the positivity of the anti-DNA topoisomerase I antibody (Scl-70) is noted. Usually found in $60 \%$ of patients with the diffuse form of SSc, and in about $40 \%$ of those with the limited form [10].

The pathophysiology of scleroderma secondary to silicosis probably occurs in the lungs previously exposed to silica through the phagocytosis of silica particles by alveolar macrophages and their production of large-scale inflammatory cytokines. In addition, there is the formation of factors that induce collagen production, leading to pulmonary fibrosis due to chronic inflammation and the action of these substances [8].

When the bronchioloalveolar lining infiltrated by macrophages and epithelial cells in high activity begins to produce a high amount of free radicals superior to the antioxidant mechanism performed by surfactants in this pulmonary alveolus, type I pneumocyte damage and increased proliferation of type II pneumocytes may occur [6].

Changes in the solubility of interleukin-2 (IL-2) receptors as a result of prolonged contact with silica, like the case here reported. The secretion of cytokines by lymphocytes, monocytes and mast cells are also fundamental stimuli for the synthesis of collagen by fibroblasts. The contact of silica with these cell groups, mainly monocytes, stimulates the secretion of IL-1, IL-6 and TNF-alpha which are factors that promote the proliferation of fibroblasts, responsible for the high production of elastin, thus promoting edema, hardening and tissue atrophy [11].

\section{References}

[1] Erasmus LD. Scleroderma in goldminers on the Witwatersrand with particular reference to pulmonary manifestations. South Afr J Lab Clin Med Suid-Afr Tydskr Vir Lab- En Kliniekw. setembro de 1957;3(3):209-31.

[2] LeRoy EC, Black C, Fleischmajer R, Jablonska S, Krieg T, Medsger TA, et al. Scleroderma (systemic sclerosis): classification, subsets and pathogenesis. J Rheumatol. fevereiro de 1988;15(2):202-5.

[3] Bramwell B. Diffuse scleroderma: Its frequency; its occurrence in stonemasons. Edinburgh Med J 1914;12:387-401.

[4] Aryal BK, Khuder SA, Schaub EA. Meta-analysis of systemic sclerosis and exposure to solvents. Am J Ind Med. 29 de agosto de 2001;40(3):271-4.

[5] Zimmermann AF, Pizzichini MMM. Atualização na etiopatogênese da esclerose sistêmica. Rev Bras Reumatol. novembro de 2013;53(6):51624.

[6] de Miranda AAM, Nascimento AC, Peixoto IL, Scrignoli JA, Lucena Cardoso M do S de, Euzébio Ribeiro SL. 
Síndrome de Erasmus - silicose e esclerose sistêmica. Rev Bras Reumatol. maio de 2013;53(3):310-3.

[7] Denton CP, Khanna D. Systemic sclerosis. The Lancet. outubro de 2017;390(10103):1685-99.

[8] Rocha LF, Luppino Assad AP, Marangoni RG, Del Rio APT, MarquesNeto JF, Sampaio-Barros PD. Systemic sclerosis and silica exposure: a rare association in a large Brazilian cohort. Rheumatol Int. maio de 2016;36(5)

[9] Velayos EE. The "CREST" syndrome. Comparison with systemic sclerosis (scleroderma). Arch Intern Med. $1^{\circ}$ de novembro de 1979;139(11):1240-4.

[10] Skare TL, Fonseca AE, Luciano AC, Azevedo PM. Autoanticorpos em esclerodermia e sua associação ao perfil clínico da doença: estudo em 66 pacientes do sul do Brasil. An Bras Dermatol. dezembro de 2011;86(6):107581.

[11] Yáñez Diaz $S$, Morán $M$, Unamuno P, Armijo M. Silica and Trichloroethylene-Induced Progressive Systemic Sclerosis. Dermatology. 1992;184(2):98-102.

Conflict of interest: The authors declare no conflicts of interest.

Acknowledgements: None.

Funding: None.
How to cite this article: Pereira FL, Portilho JVM, Meira JPVR, de Paula CDR. Erasmus syndrome presented as CREST syndrome with Scl-70 positivity: a case report. Brazilian Journal of Case Reports. 2021 Jul-Sep; 01(3):90-94. 